\title{
A Study on the Reclamation and Ecological Restoration in Subsidence Land in Chinese Coal Mine Area
}

\author{
Hui Yue ${ }^{1, *}$ and Ying Liu $^{2}$ \\ College of Geomatics, Xi'an University of Science and Technology, Xi'an 710054, Shaanxi, China
}

\begin{abstract}
Arbuscular mycorrhizal fungi (AMF) technology of bioremediation becomes one of the most hotspots in the research on coal-mining subsidence land. This article based on amorpha fruiticosa planting in the mining subsidence of Shendong mining area as a study object, arbuscular mycorrhizal fungi was vaccinated on amorpha fruiticosa after different monitor time, respectively measures are used to analyze its effect on the growth of plant and on rhizosphere soil physical properties. The correlation between hyphae density and Olsen-P of rhizosphere is analyzed. By using regression analysis, we found that in different monitoring time, hyphae density and effective phosphorus in September had better linear fitting than that in June, which is closely associated with development time of mycorrhizal. With the time passing by, the correlation of vaccination between hyphae density and effective phosphorus content is gradually decreased; however, the positive correlation of un-vaccinated is gradually emerged. The results of mycorrhizal bioremediation on mining subsidence in Shendong mining area prove that vaccination not only could effectively promote growth and development of amorpha fruiticosa in macroscopic, but also could improve the growth matrix conditions in microscopic.
\end{abstract}

Keywords: Arbuscular mycorrhizal fungi, coal-mining subsidence land, reclamation and ecological restoration.

\section{INTRODUCTION}

China as a big country of coal, the proportion of coal is over $70 \%$ of China's energy consumption structure, with the development of coal industry, it caused a lot of environmental problems. With more and more coal resources mined from underground in recent years, ground subsidence and environmental disaster problems happened [1]. The restoration of ecological environment in mining subsidence area was led to regional economic and social stability. Shendong mine area is currently China's largest coal production base located in the arid and semi-arid inland areas, which is the junction of Shaanxi, Inner Mongolia and Shanxi. It suffered a lot from the climatic conditions, such as the water shortage, scarce rainfall, evaporation, large temperature difference between day and night, a fragile ecological environment, land desertification and so on. Underground mining caused surface subsidence, the farmland lost their original productivity, combined with its own climatic conditions not conducive to plants growth, mining for the destruction of the ecological environment directly affect the sustainable development of Shendong mining area. By the end of 2008, the total area of coal mining subsidence area as $7800 \mathrm{hm}^{2}$, and with an annual increase of subsidence area an area of $200 \mathrm{hm}^{2}$. Arbuscular mycorrhizal fungi (AMF) is widely found in terrestrial ecosystems, with more than $80 \%$ of terrestrial plants forming a mutually beneficial symbiotic relationship [2-4]. As a key symbiont in the terrestrial ecosystem, AMF under the condition of poor soil, can improve plant by its massive hyphae network of mineral nutrient absorption, promote the formation of soil aggregate [5]. In extreme circumstances, by improving the nutritional enhancement of plant resistance to heavy metals, the ability of drought resistance, resistance to insect pests. On the basis of the soil micro ecological environment can be improved [6]. Based on physiological and ecological characteristics of arbuscular mycorrhizal fungi, we inoculated arbuscular mycorrhizal fungi in Amorpha fruticosa which in the Shendong mining area of coal mining subsidence land, study its influence of soil physical and chemical properties, in order to explore a new method which suitable for microbial reclamation of coal mining subsidence area. It can provide theoretical data and practical basis for AMF technology large-scale popularization and application of the microorganism remediation in the mining area land. In conclusion, AMF technology is of great practical significance for reclamation and ecological restoration in subsidence area.

\section{METHOD AND MATERIALS}

\subsection{Test Site}

Test site selected in Shenmu county of Shaanxi province. This site located in the transition zone between ordos plateau and the loess plateau, northern connected with Mu Us Sandy Land and southern linked with the loess plateau, which is the evolution of transitional zone of loess plateau. It is two phase tregion for water erosion and wind erosion. The test base was built on three gully beam, which belongs to a typical arid and semi-arid continental monsoon climate, annual average precipitation was $362 \mathrm{~mm}$, mainly concentrated in June to September, uneven distribution of precipitation inter-annual and 
intra-annual; annual evaporation is 2297.4 to $2838.7 \mathrm{~mm}$, which is 6 to 7 times of the precipitation. The annual average temperature is $7.3^{\circ} \mathrm{C}$, the heat index changed dramatically. Where the soil was barren and soil organic matter content was so low, lack of $\mathrm{N}, \mathrm{P}, \mathrm{K}$, poor water protecting fertilizer and corrosion resistance. Soil basic physical and chemical properties are as follows: $16.7 \%$ of saturated water capacity, $\mathrm{pH}$ value of 8.6 , the electrical conductivity $0.61 \mathrm{~ms} / \mathrm{cm}$, effective phosphorus is $3.4 \mathrm{mg} / \mathrm{kg}$.

\subsection{Material and Method}

The experiment use amorpha fruiticosa as host plant, Glomus mosseae (G.m) and Glomus albidus (G.a) are selected as inoculant. The experiment site was designed to three areas named as control (CK), G.m and G.a, the area of CK, G.m and G.a is $3000 \mathrm{~m} 2$. After amorpha fruiticosa was planted, , planting spacing is $1 \mathrm{~m} \times 2 \mathrm{~m}$, arbuscular mycorrhizal fungi vaccination applied with seeding access, the weight is 20 gram each plant. The monitor time were 2010-09-16, 2011-06-10, 201109-13, 2012-06-15, 2012-09-25, 2013-06-16 and 2013-09-20, each time selected 15 samples in areas of

G.m, G.a, and CK, 15 random positions were selected under the "S" shape method from each district, and roots and fresh rhizosphere soil samples were collected and numbered in sequence. Monitoring parameters included plant height, ground diameter and crown breadth and survival rate. After soil samples took back to the lab, subsequently measured index include mycorrhizal infection rate, hyphae length and Olsen-P content. Mycorrhizal infection rate adopt the method of Haymen, hyphae length used the grid intersection method, Olsen-P content using molybdenum antimony colorimetric method $[7,8]$.

\section{RESULTS}

\subsection{The Influence of Mycorrhizal Inoculation on Sur- vival Rate}

The influence of survival rate in different treatment of mycorrhizal inoculation as shown in Fig. (1). Monitoring time from the beginning 2010.09.16 to the last time 2013.09.20, in the period of 4 years, comparing different treatment survival rate can be found that mycorrhizal inoculation can obviously increase the survival rate in G.m and G.a , up to more than $30 \%$.Overall, different mycorrhizal effect on the survival rate was not significant, but inoculation of G.m makes a little higher survival rate than the inoculation of G.a. From the point of inter-annual variation trend of survival rate, in each year, survival rate in June is lower than in September, and lower than the inoculation plants is more apparent, the reason probably was the pilot plant from moisture from fertility natural management method, the survival rate will be slight fluctuations. Moreover,the arrival of the rainy season in Shendong mining area always from June to September in a year, also may be caused by different adaptability of plants in winter. In general, mycorrhizal inoculation plants increased the ability to resist the extreme environment, the survival rate of inoculation plants in G.m and G.a were significantly higher than the area of CK.

\subsection{The Influence of Mycorrhizal Inoculation on Mycor- rhizal Infection Rate}

Mycorrhizal infection rate is not only describe the degree of roots infection by mycorrhizal fungi, but also reflect the affinity of arbuscular mycorrhizal formation and mycorrhizal fungi on symbionts [9]. Mycorrhizal fungi mainly infect new root germination, root growth and root germination were helpful for mycorrhizal infection and hyphae formation; on the contrary, mycorrhizal infection rate would declines. From the period of monitoring time from 2010.09.16 to 2013.09.20, the infection rate in G.m and G.a area is significantly higher than the area of CK. However, the mycorrhizal infection rate in CK area achieves above $30 \%$ in 7 monitor times, from the microscope to observe the mycorrhizal fungi infection of CK is obvious more than indoor test, this due to the soil exists certain quantity and quality native species and infected on root system (Fig. 2).

As the growth time passing by, the infection rate of G.m and G.a area appear certain fluctuation, the rule is shown as: mycorrhizal infection rate in June is lower than in September each year, showed as "W" trend of fluctuations, and it is due to growth and development time of mycorrhizal fungi in the soil. In Shendong mining area, the rainy season begins from June to September, and is also the most exuberant and development period for plants, mycorrhizal fungi easily form symbionts with plants, nutrient flow frequently between each
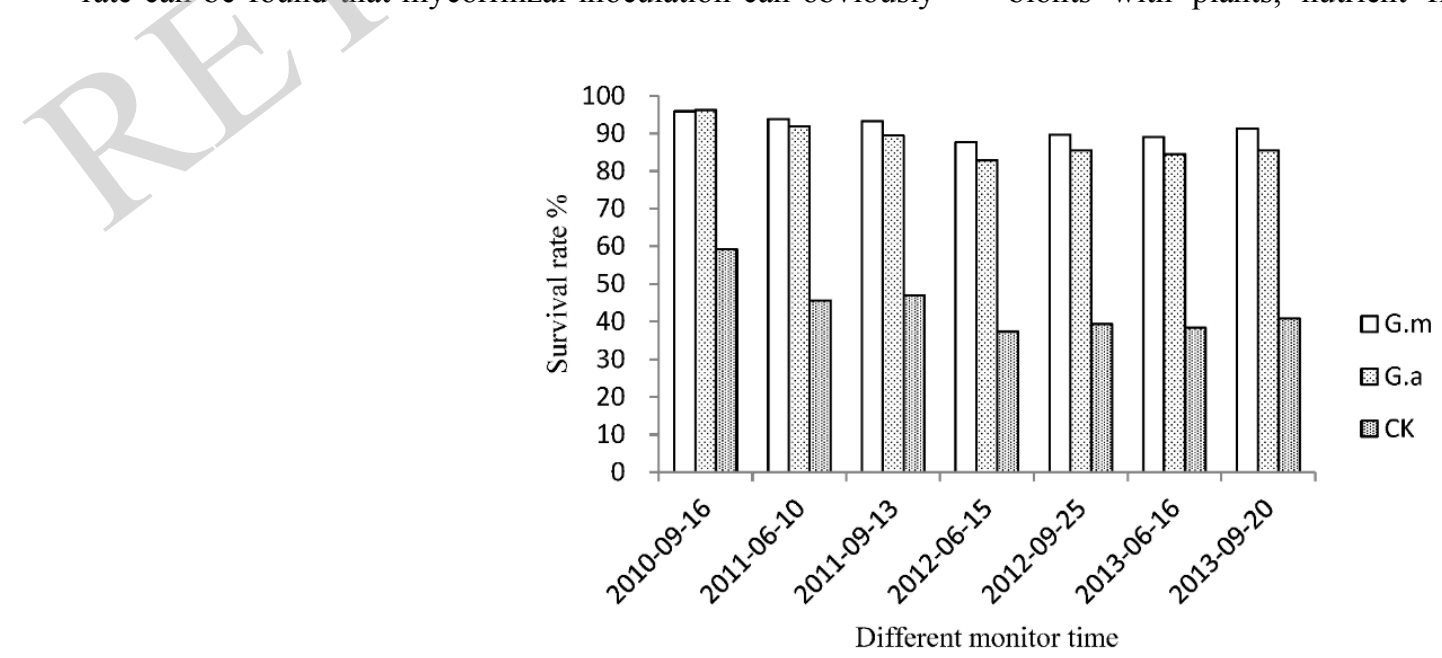

Fig. (1). Effect of AMF in different areas on survival rate. 


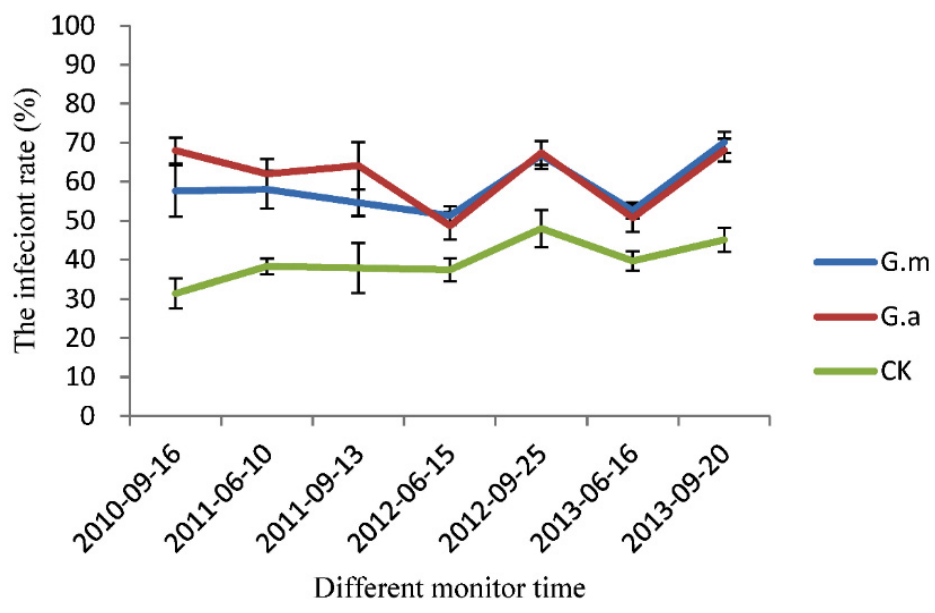

Fig. (2). Effect of AMF in different areas on infection rate.

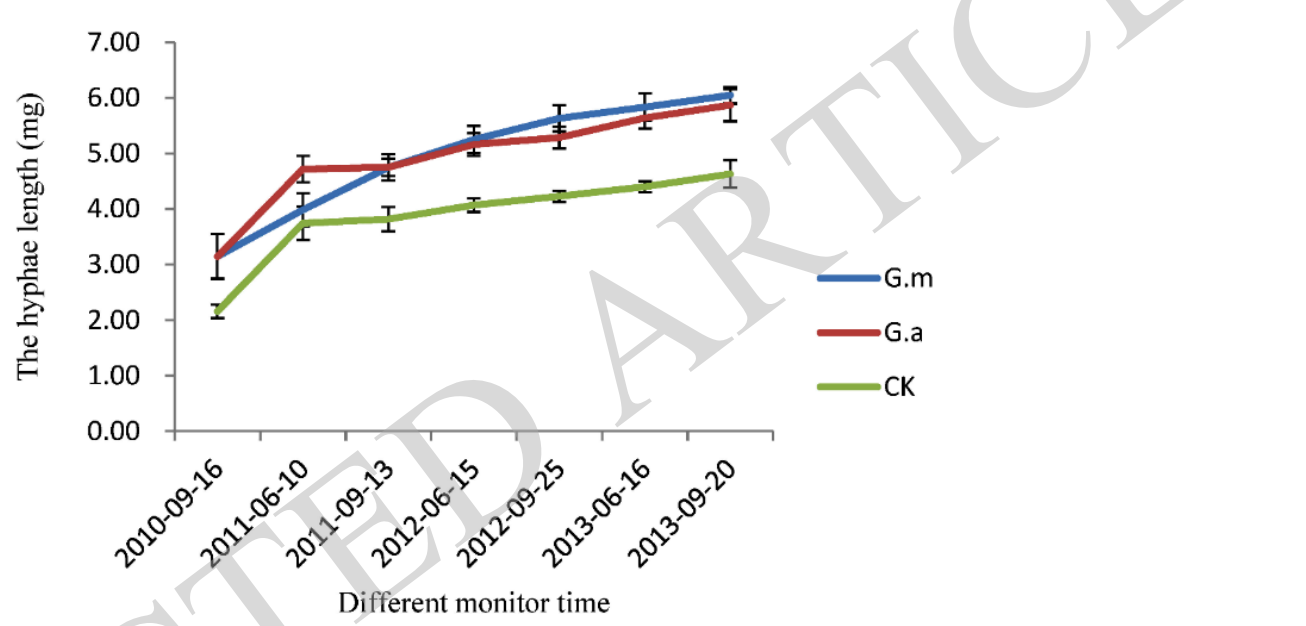

Fig. (3). Effect of AMF in different areas on hyphae length.

other, therefore, the mycorrhizal infection rate is higher. In the next year of September after and before the arrival of the rainy season, the change of rainfall and temperature is not suitable for the growth of mycorrhizal fungi, mycorrhizal fungi spores dormant at this time, therefore, mycorrhizal infection rate is low before the rainy season coming in June.

\subsection{The Influence of Mycorrhizal Inoculation on Hyphae Length}

The hyphae length reflects the arbuscular mycorrhizal effects on plant rhizosphere [10]. Unit of rhizosphere soil of mycelium length is larger, the more conducive to the root system on soil nutrients and moisture absorption and transportation, the more can promote plant growth and improve the resistance of plants (Fig. 3).

Monitoring results show that: from 2010.09.16 to 2013.09.20 as the extension of inoculation time, hyphae length in different treatment area present the same rule, hyphae length appear as G.m G.a CK, Inoculation can improve the hyphae length in soil, up to more than $40 \%$. Inoculation area and control area with hyphae length are increased with the growth time, inoculation area and control area reached significant difference, but hyphae length between G.m and G.a had no significant difference in plant rhizosphere. By tracking hyphae length change of different treatments of rhizosphere soil, the monitoring results show that various growth after four years had been established a stable arbuscular mycorrhizal symbiosis.

\subsection{Correlation Analysis Between Hyphae Length and Olsen-P}

Mycelium length can be considered to be an important index of mycorrhizal infection efficiency, research has confirmed that mycorrhizal inoculation can increase plant absorption of phosphorus [11]. Unit mass of mycelium length, the greater the soil contained in the hypha and secretion, the more the more soil aggregate (size is less than $0.25 \mathrm{~mm}$ ), the easier it is to form stable soil glue particles. Under the condition of the wild field, to verify whether mycelium length of soil effective phosphorus in plant rhizosphere effect, by use of EXCEL of mycelium length can be obtained by seven sampling test analysis and linear regression equation of effective phosphorus content (Table 1).

The analysis found that there is a linear correlation between various rhizosphere mycelium length and effective phosphorus content. Correlation coefficient values from 0.1032 to 0.1032 , correlation coefficient of G.m and G.a area was larger than CK area, but there is no significant difference 

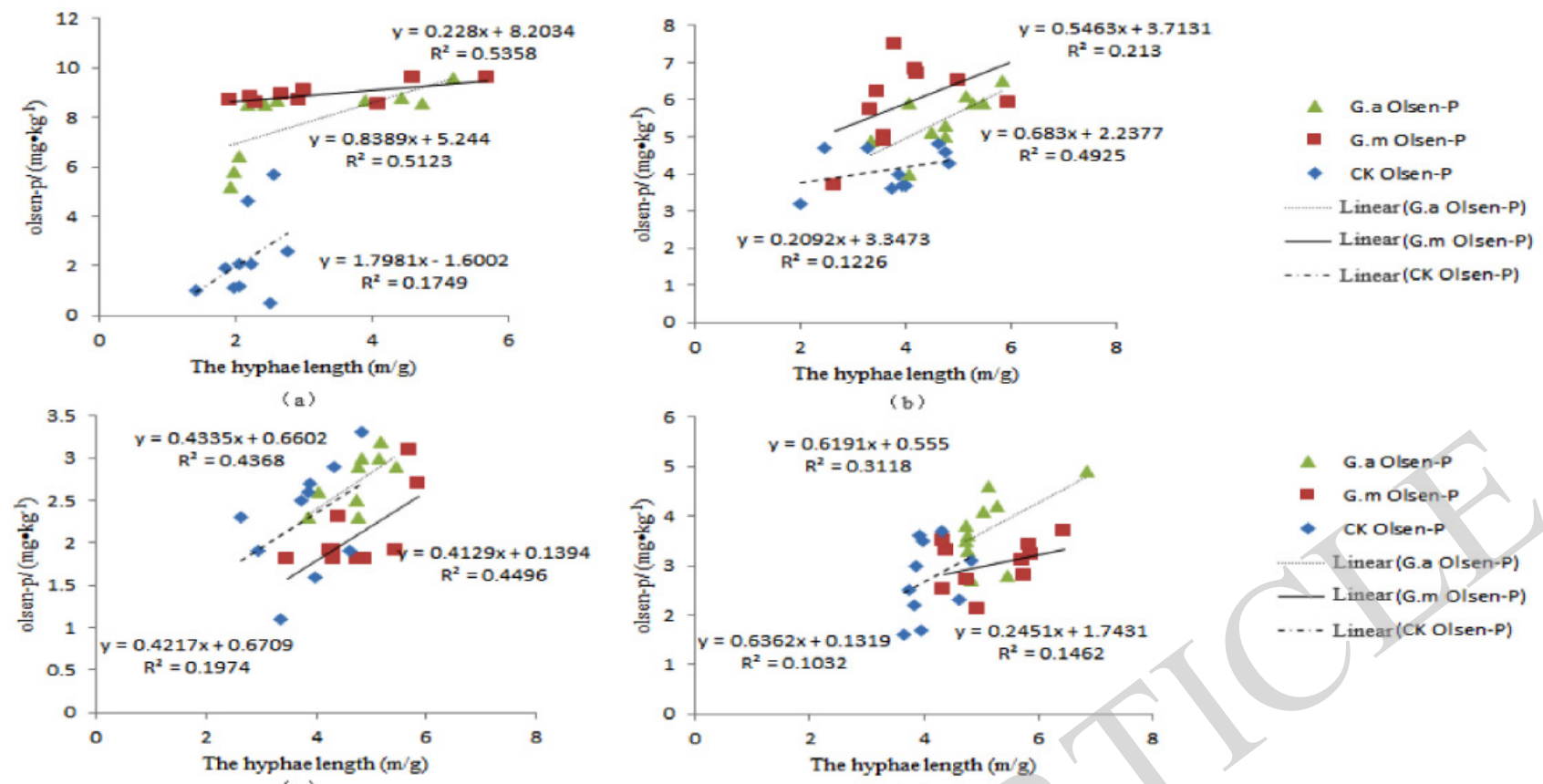

(b)

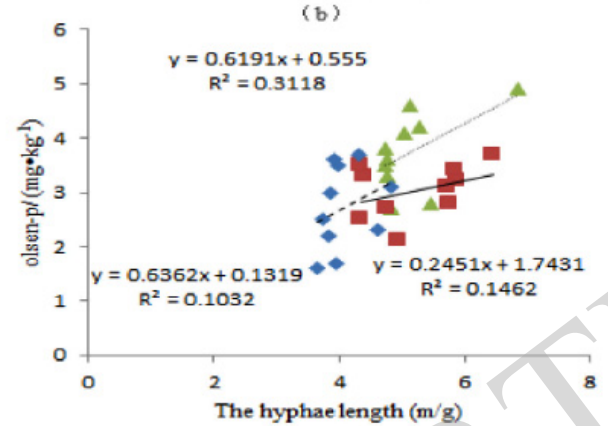

- G.a Olsen-P

- G.m Olsen-P

- CKOlsen-P

- Linear (G.a Olsen-P)

— Linear (G.m Olsen-P)

-... Linear (CK Olsen-P)

(c)

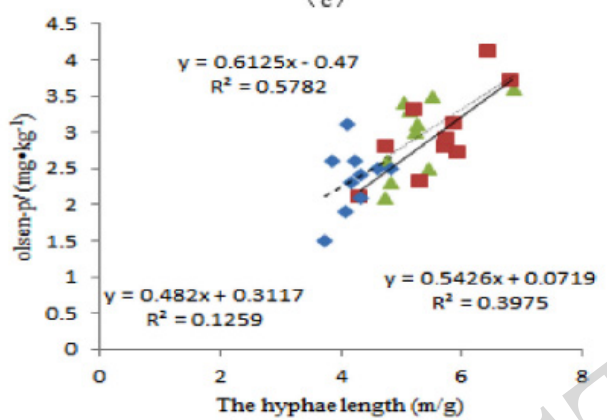

(d)

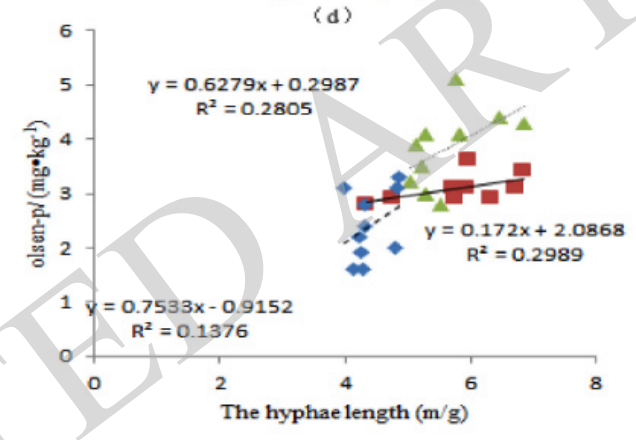

4 G.aolsen-P

- G.m Olsen-P

- CKOlsen-P

Linear (G.a Olsen-P)

_ Linear (G.m Olsen-P)

(f)
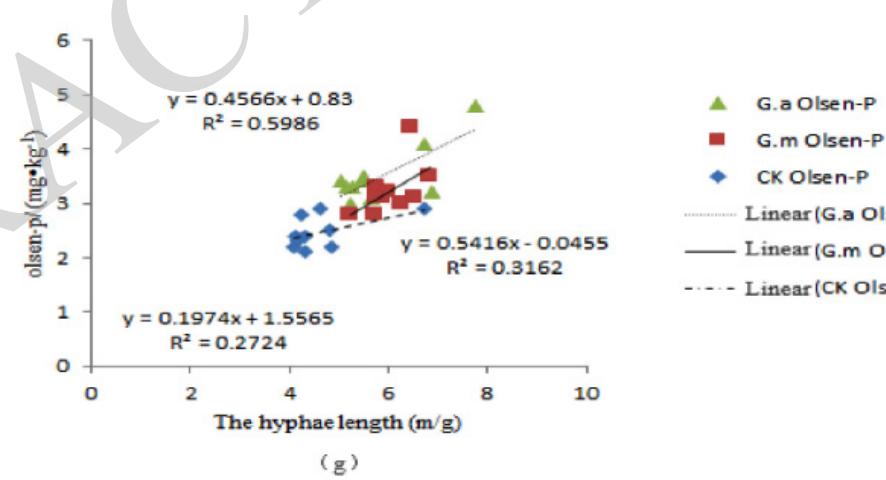

- G.m Olsen-P

- CK Olsen-P

….... Linear (G.a Olsen-P)

__ Linear (G.m Olsen-P)

-.... Linear (CK Olsen-P)

-...- Linear (CK Olsen-P)

Fig. (4). Correlation analysis between hyphae length and Olsen-P in different time.

(a) 2010-09-16, (b) 2011-06-10, (c) 2011-09-13, (d) 2012-06-15, (e) 2012-09-25, (f) 2013-06-16 and (g) 2013-09-20.

between G.m and G.a. Correlation coefficient value of G.m and G.a varies changed dramaticly and in CK area change is relatively stable, correlation coefficient value of G.m and G.a area appeared as w-type fluctuations, generally had smaller values in the trough when in June each year, and rise to wave in September, comparing CK correlation coefficient value varies was small but also presents the trend of w-type fluctuations.

The different treatments of linear regression equation between rhizosphere mycelium length and effective phosphorus content was showed in Fig. (4), always reflected significant correlation in September, including the inoculation area (2010-09-16, G.m=0.732, G.a $=0.716, \quad \mathrm{p}<0.05 ; 2011-09-13$, $\mathrm{G} . \mathrm{m}=0.671$, G. $\mathrm{a}=0.0 .661, \mathrm{p}<0.05 ; 2012-09-25$, G.m=0.760, $\mathrm{p}<0.05 ; 2013-09-20$, G.a $=0.774, \mathrm{p}<0.05)$ and totally emerged six significant difference. However, it had poor correlation in June, with only one significant difference appeared (2011-06$10, \mathrm{G} . \mathrm{a}=0.702, \mathrm{p}<0.05)$. The $\mathrm{CK}$ area in all previous monitoring soil and there was no significant difference between effective phosphorus content and mycelium length, the reason 
Table 1. The correlation coefficient between olsen-P and hyphae length of Amorphafruticosa $L$.

\begin{tabular}{|c|c|c|c|c|c|}
\hline \multirow{2}{*}{$2010-09-16$} & G.m & $0.732^{*}$ & \multirow{2}{*}{$2012-09-25$} & G.m & $0.760^{*}$ \\
\hline & $\mathrm{CK}$ & 0.418 & & $\mathrm{CK}$ & 0.355 \\
\hline 2011-06-10 & $\mathrm{CK}$ & 0.350 & 2013-06-16 & $\mathrm{CK}$ & 0.371 \\
\hline \multirow[b]{2}{*}{ 2011-09-13 } & G.m & $0.671^{*}$ & \multirow[b]{2}{*}{ 2013-09-20 } & G.m & 0.562 \\
\hline & G.a & $0.661^{*}$ & & G.a & $0.774^{*}$ \\
\hline \multirow[t]{2}{*}{$2012-06-15$} & G.a & 0.558 & & & \\
\hline & $\mathrm{CK}$ & 0.321 & & & \\
\hline
\end{tabular}

Notes: " means significant correlation at $\mathrm{p}<0.05$ level, the same hereafter

could be underground hyphae network of mycorrhizal fungi accelerated activity with the arrival of the rainy season from June to September every year, the spore germination, root hyphae infect plant roots, after the rainy season with the decline of temperatures and less rainfall, underground hyphae network activity is reduced, mycorrhizal infection rate was decreased and root hyphae secretion is also reduced.

\section{DISCUSSION}

Through inoculated arbuscular mycorrhizal fungi on different treatments in Shendong mining area, mutual symbiosis formed between plants and mycorrhizal fungi, expanded the roots and the hyphae in contact with the soil, the inoculation plants absorb more nutrients than in the CK area plants. Experiments showed that the hyphae phosphorus absorption rate is about four times that of root hair, root hyphae can stretch to the root table $8 \mathrm{~cm}$ absorption of phosphorus in the soil, mycorrhizal hyphae can store a more phosphorus than absorbed by plant roots, phosphorus mainly inorganic phosphorus forms of transport in plants and transport rate of $2 \mathrm{~mm} / \mathrm{h}$, phosphorus transport in mycelium is in the form of polyphosphate particles [12-14]. As there is no diaphragm in arbuscular mycorrhizal fungi hyphae, phosphorus can transport within the root hyphae in two-way sides, and the transport rate could reached $20 \mathrm{~mm} / \mathrm{h}$, which was tenfold within the root rate and root makes external hyphae of soil phosphorus, it was able to be quickly transported to the root mycelia again by polyphosphate particles which are decomposed into simple inorganic phosphorus transferred to the host plant [15]. In the wild field experiment, the inoculation area and CK area plant rhizosphere absorb effective phosphorus ability differences reflected in the differences in plant biomass on the ground, survival rate, plant height, ground diameter and crown which were significantly better than CK area. This experiment was conducted in Shendong mining subsidence land area, soil effective phosphorus content was in lower level, the test results showed that the mycelium length and plant rhizosphere effective phosphorus content exist certain linear fitting, which supported the view that in some extent, under the condition of low phosphorus, efficiency of mycorrhizal infection is one of the leading factors of capacity difference in plant phosphorus absorption.

\section{CONCLUSION}

(1) In the wild field under the condition of inoculation of arbuscular mycorrhizal fungi promote various survival rate above $30 \%$, and the inoculation can significantly improve the aboveground biomass of plants. The inoculation increased the ability of mycorrhizal fungi infect root, mycorrhizal infection rate is influenced by mining area climate conditions, presents the w-type fluctuations, before the coming of rainy season in June each year in the trough, and in September after the rainy season in the wave.

(2) Effective phosphorus content on different treatments in the rhizosphere and mycelium length appeared positive correlation, the inoculation area correlation coefficient is higher than CK area. Correlation coefficient and mycorrhizal infection rate change trend, show w-type fluctuations, and it is related to the rainfall in mining area, temperature and other weather conditions and underground hyphae network development.

\section{CONFLICT OF INTEREST}

The authors confirm that this article content has no conflict of interest.

\section{ACKNOWLEDGEMENTS}

This paper was funded by Natural Science Foundation of China (41401496), Xi'an University of science and Technol- 
ogy Basic Fund (201306) and Xi'an University of science and Technology Research Fund for the Doctoral Program (2014QDJ061).

\section{REFERENCES}

[1] M. Yu, Y. Bi, and C. Zhang, "Lasting improvement effects of arbuscular mycorrhizal fungi and Bradyrhizobium japonicum on rhizosphere soil environment in mining subsidence," Transactions of the Chinese Society of Agricultural Engineering, vol. 29, no. 8, pp. 242-248, 2013. (in Chinese with English abstract)

[2] M. G. A. V. der Heijden, J. N. Klironomos, M. Ursic, M. Peter, S. E. Ruth, B. Thomas, W. Andres, and R. S. Ian, "Mycorrhizal fungal diversity determines plant biodiversity, ecosystem variability and productivity," Nature, vol. 396, no. 5, pp. 69-72, 1998.

[3] S. F. Wright, S. M. Franke, J. B. Morton, and A. Upadhyaya, "Time course study and partial characterization of a protein on hyphae of arbuscular mcyrrohzal fungi during active colonization of roots," Plant and Soil, vol. 181, pp. 193-203, 1996.

[4] A. Barua, S. D. Gupta, M. A. U. Mridha, and M. K. Bhuiyan, "Effect of arbuscular mycorrhizal fungi on growth of Gmelina arborea in arsenic-contaminated soil," Journal of Forestry Research, vol. 21, no. 4, pp. 423-432, 2010.

[5] J. Marleau, Y. Dalpé, M. St-Arnaud, and M. Hijri "Spore development and nuclear inheritance in arbuscular mycorrhizal fungi," BMC Evolutionary Biology, vol. 11, no. 1, pp. 1-11, 2011.

[6] Z. Sasvári, L. Hornok, and K. Posta, "The community structure of arbuscular mycorrhizal fungi in roots of maize grown in a 50-year monoculture," Biology and Fertility of Soils, vol. 47, no. 2, pp. 167-176, 2011.

[7] J. M. Phillips, and D. S. Haymen, "Improved procedures for clearing and staining parasitic and vesicular-arbuscular mycorrhizal fungi for rapid assessment of infection," Transactions of the British Mycological Society, vol. 55, no. 1, pp. 158-161, 1970.
[8] I. Jakobsen, L. K. Abbott, and A. D. Robosen, "External hyphae of vesicular-arbuscular mycoorhizal fungi associated with Trifolium subterraneum L. Spread of hyphae and phosphorus inflow into root," New Phytol, vol. 120, pp. 371-380, 1992.

[9] M. N. El-Mesbahi, R. Azcón, J. M. Ruiz-Lozano, and A. Ricardo, "Plant potassium content modifies the effects of arbuscular mycorrhizal symbiosis on root hydraulic properties in maize plants," $M y$ corrhiza, vol. 22, no. 7, pp. 555-564, 2012.

[10] D. P. Janos, S. Garamszegi, and B. Beltran, "Glomalin extraction and measurement," Soil Biology and Biochemistry, vol. 40, no. 3, pp. 728-739, 2008.

[11] J. Saxena, S. Chandra, and L. Nain, "Synergistic effect of phosphate solubilizing rhizobacteria and arbuscular mycorrhiza on growth and yield of wheat plants," Journal of Soil Science and Plant Nutrition, vol. 13, no. 2, pp. 511-525, 2013.

[12] Y. Tian, Y. Lei, Y. Zheng, and Z. Cai, "Synergistic effect of colonization with arbuscular mycorrhizal fungi improves growth and drought tolerance of Plukenetia volubilis seedlings," Acta Physiologiae Plantarum, vol. 35, no. 3, pp. 687-696, 2013.

[13] S. E. D. Hassan, A. Liu, S. Bittman, T. A. Forge, D. E. Hunt, M. Hijri, and S. A. Marc, "Impact of 12-year field treatments with organic and inorganic fertilizers on crop productivity and mycorrhizal community structure," Biology and Fertility of Soils, pp. 1-13, 2013.

[14] S. E. Smith, I. Jakobsen, M. Grønlund, and F. A. Smith, "Roles of arbuscular mycorrhizas in plant phosphorus nutrition: interactions between pathways of phosphorus uptake in arbuscular mycorrhizal roots have important implications for understanding and manipulating plant phosphorus acquisition," Plant Physiology, vol. 156, no. 3, pp. 1050-1057, 2011.

[15] B. J. Cardinale, J. E. Duffy, A. Gonzalez, David U. Hooper, C. Perrings, P. Venail, A. Narwani, G. M. Mace, D. Tilman, D. A. Wardle, A. P. Kinzig, G. C. Daily, M. Loreau, J. B. Grace, A. Larigauderie, D. S. Srivastava, and S. Naeem, "Biodiversity loss and its impact on humanity," Nature, vol. 486, no. 7, pp. 59-67, 2012.

Received: Febuary 09, 2015

(C) Yue and Liu; Licensee Bentham Open.

This is an open access article licensed under the terms of the (https:/creativecommons.org/licenses/by/4.0/legalcode), which permits unrestricted, noncommercial use, distribution and reproduction in any medium, provided the work is properly cited. 